\title{
Chitosan Loaded Ketorolac Tromethamine Nanoparticles for Improved Ocular Delivery in Eye Inflammation
}

\author{
Shaweta Sharma ${ }^{1, *}$, Akhil Sharma ${ }^{2}$, Udayveer Singh Sara ${ }^{3}$, Shekhar Singh ${ }^{4}$ \\ ${ }^{1}$ College of Pharmacy, IIMT Group of Institutions, Greater Noida, Uttar Pradesh, INDIA. \\ ${ }^{2}$ Department of Pharmaceutics, R.J College of Pharmacy, Raipur, Aligarh, Uttar Pradesh, INDIA. \\ ${ }^{3}$ College of Pharmacy, Dr. M.C. Saxena Group of institutions, Lucknow, Uttar Pradesh, INDIA \\ ${ }^{4}$ College of Pharmacy, Teerthanker Mahaveer University, Moradabad, Uttar Pradesh, INDIA.
}

\begin{abstract}
Aim: Ketorolac tromethamine (KT) is highly effective in treating post-operative eye inflammation, allergic conjunctivitis as well other ailments. It is reported that USFDA has approved a $0.45 \%$ ophthalmic solution of KT (Acuvail, Allergan, Inc) for the treatment of pain and inflammation after cataract surgery. However, the bioavailable amount of an ocular dosage form is very low due to continuous defensive mechanism in the eye. Thus the aim of present study was to improve the bioavailability of KT via sustained release using the polymer matrix (Chitosan) as a carrier. Materials and Methods: Nanoparticles of Ketorolac tromethamine were prepared by ionotropic gelation method. Design expert software was used to evaluate the effect of chitosan and tripolyphosphate (TPP) concentration on particle size and entrapment efficiency of nanoparticles. Prepared nanoparticles were physico-chemically characterized for \% yield, entrapment efficiency, particle size and Zeta potential, surface morphology, in-vitro drug release, release kinetics and stability studies. In accordance with the evaluation parameters and results obtained from factorial design, an optimized batch was designed and evaluated for above mentioned parameters. Results: The optimized batch thus prepared was having Percentage yield (66.4\%), Percentage Entrapment Efficiency (61.65\%), Particle size (153.9 nm), Zeta Potential (-21.8) and percentage drug release $(94.368 \pm 0.181 \& 92.797 \pm 0.150 \%$ in PBS and STF ( $\mathrm{pH} 7.4$ ) respectively). Results of release kinetic study revealed that drug dissolution followed Zero order release kinetics model. No physicochemical changes were seen when stored at accelerated conditions. Conclusion: It was concluded that the principle adopted behind this research work will provide impetus for future researchers to carry out such formulations of wider variety of drugs rendering highly economical utility.
\end{abstract}

Key words: Ketorolac tromethamine, Chitosan, Tripolyphosphate, Nanoparticles, Design expert.

\section{INTRODUCTION}

Inflammation is the indication of cellular and vascular response of the host tissue to injury which may be inflicted by physical or chemical agents, invasion of pathogens, ischemia, and excessive (hypersensitivity) or inappropriate (autoimmunity) operation of immune mechanisms. Post-operative inflammation includes distracted aqueous-blood barrier, excessive blood flow in conjunctival vessels, miosis, elevated IOP, intervened by COX pathways. ${ }^{1-2}$ Ocular inflammation most frequently hastens due to infection, allergens, surgical intervention or trauma. ${ }^{3}$ Various ocular problems/diseases i.e. intraoperative miosis (during cataract surgery), postoperative inflammation, cystoid macular edema (CME) following cataract extraction, seasonal allergic conjunctivitis, ocular dis-
Submission Date: 15-03-2018; Revision Date: 15-05-2018; Accepted Date: 14-08-2018

DOI: 10.5530/ijper.52.4s.99 Correspondence:

Dr. Shaweta Sharma, IIMT College of Pharmacy, Greater Noida, Uttar Pradesh, INDIA. Phone: +91 9068978444 E-mail: shaweta1984@gmail. com

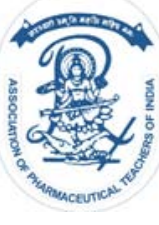

www.ijper.org 
comfort (pain and photophobia) after refractive surgery, Diabetic retinopathy (DR) and Diabetic macular edema (DME) are prevented/treated by various drugs belonging to NSAID class. ${ }^{1-4}$ Eye-drops accounts for the $90 \%$ of currently accessible conventional ophthalmic formulations. The bioavailable amount of an ocular dosage form is very low due to continuous defensive mechanism in the eye. The instilled amount of drug is continuously wiped out from the retinal flora because of blinking and involuntary lachrymation. Also, the faster absorption of applied drugs is more massed by the anatomy, physiology and barrier functions of cornea. ${ }^{5}$ Nanoparticles have been formulated as eye drops or injectables to surmount ocular obstacles faced after administration. Better drug pharmacodynamics and pharmacokinetics, immunogenicity, bio recognition and non-specific toxicity can be achieved to improve drug efficacy by loading drugs in the nanoparticles. ${ }^{6-9}$ Chitosan nanoparticles are good drug carriers because of their good biocompatibility and biodegradability, and can be readily modified. ${ }^{10-11}$ Ketorolac tromethamine (KT) belongs to pyrrolo-pyrrole group of NSAIDs. Its chemical name is ( \pm )-5-benzoyl-2,3-dihydro- $1 \mathrm{H}$-pyrrolizine-1-carboxylic acid, compound with 2-amino2-(hydroxymethyl)-1,3-propanediol (1:1). It is highly effective in relieving pain after radial keratotomy (RK), photorefractive keratectomy (PRK), laser in situ keratomileusis (LASIK); acute pseudophakic cystoid macular edema (PCME) and to treat allergic conjunctivitis pertaining to inhibition of ocular PG synthesis. ${ }^{12-13}$ Hence, the present worker conceptualized "Chitosan loaded Ketorolac tromethamine nanoparticles for improved ocular delivery in Eye inflammation" that would fulminate into improved therapy. The outcomes of research work, in reference, would contribute to the society in getting rid of such problems by recognizing ultimate ease and least negligence to maintain the drug therapy i.e. least possible frequency of administration, higher ocular residence time and thus sustained longer duration of action.

\section{MATERIALS AND METHOD}

\section{Materials}

Ketorolac tromethamine was procured from Panchsheel Organics Ltd, Indore. Chitosan (Medium grade; 400 KD) was purchased from Evonik Industries, Mumbai, MHA. Other chemicals i.e. Glacial acetic acid, Span-80, Ethanol, Sodium hydroxide, Sodium chloride, Sodium bicarbonate, Calcium chloride dihydrate, Sodium tripolyphosphate, Potassium dihydrogen phosphate were procured from various companies.

\section{Methods}

\section{FTIR and TLC study}

Drug (Ketorolac tromethamine)-excipient compatibility was checked by adopting IR spectroscopy and densitometric TLC analyses. Infra-red spectra of pure drug alone and with chosen ingredients were recorded on FTIR (Shimadzu IR Affinity ${ }^{-1}$ ) spectroscopy at a resolution of $2 \mathrm{~cm}^{-1}$ ranged from 4000 to $400 \mathrm{~cm}^{-1}$ using $\mathrm{KBr}$ discs. Ketorolac tromethamine was analyzed densitometrically using combination of glacial acetic acid: acetone: dichloromethane (mobile phase) in ratio 1:1:9 \% v/v, respectively. Obtained spots were detected at $322 \mathrm{~nm}^{14}$

\section{Preparation of Ketorolac tromethamine loaded Chitosan nanoparticles}

Drug (Ketorolac tromethamine) laden nanoparticles were produced by ionotropic gelation method using chitosan and sodium tri-polyphosphate (Na-TPP). Prepared product (suspension) was centrifuged (Remi, Mumbai, India) for $15 \mathrm{~min}$. at $12000 \mathrm{rpm}$. Sediment was freeze dried (Lyophilizer, Biogen-model no BGS214, India) for $48 \mathrm{~h}$. The obtained nanoparticles were stored under dehydrated conditions for further studies (Figure 1). ${ }^{15}$

\section{Experimental design}

Design Expert (Version 9.0, Stat-Ease Inc., Minneapolis, $\mathrm{MN}$ ) was used for optimization study of ketorolac tromethamine nanoparticles consisted of 2 independent factors i.e. amount of chitosan (X1) and sodium tri-poly phosphate (X2) which were evaluated, at 3 levels $(-1,0,1$ i.e. 100, 200 and 300 respectively) and 9 experimental trials were performed with reference to particle size and percent (\%) entrapment as dependent variables (Table 1). All other processing variables were kept constant throughout the study. ${ }^{16}$

\section{Physicochemical characterization of Ketorolac tromethamine nanoparticles}

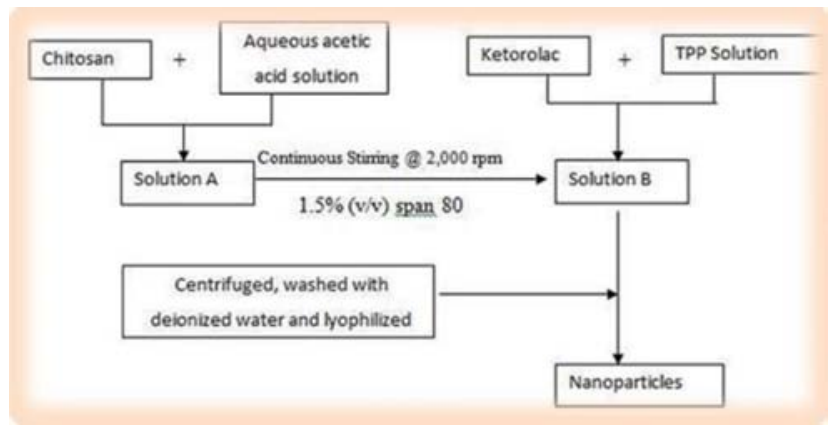

Figure 1: Ketorolac tromethamine loaded Chitosan nanoparticles. 
Table 1: Independent and Dependent variables (Coded and actual values).

\begin{tabular}{|c|c|c|c|c|c|c|c|c|}
\hline \multicolumn{3}{|c|}{ Variables } & \multicolumn{3}{c|}{$\begin{array}{c}\text { Coded values } \\
\text { (Independent variables) }\end{array}$} & \multicolumn{3}{c|}{$\begin{array}{c}\text { Actual values } \\
\text { (Independent variables) }\end{array}$} \\
\hline \multirow{2}{*}{$\begin{array}{c}\text { Drug } \\
\text { Ketorolac }\end{array}$} & Independent variables & $\begin{array}{c}\text { Dependent } \\
\text { Variables }\end{array}$ & Low & Medium & High & Low & Medium & High \\
\cline { 2 - 11 } & amount of chitosan (X1) & particle size & -1 & 0 & 1 & 100 & 200 & 300 \\
\cline { 2 - 11 } & sodium tri- poly phosphate solution (X2) & $\%$ entrapment & -1 & 0 & 1 & 100 & 200 & 300 \\
\hline
\end{tabular}

The average diameter and zeta potential of drug-loaded nanoparticles were measured by dynamic light scattering method using Zetasizer nano zs (Malvern instrument ltd., Worcestershire, UK). Surface morphology was used to determine the shapes and distribution of particles and measured by SEM (XL series Quanta FEI 200F).

\section{In-vitro Drug release}

Drug release from drug-loaded nanoparticles was carried out by suspending the prepared nanoparticles in PBS (phosphate buffer saline, $\mathrm{pH}$ 7.4) in a conical flask $(100 \mathrm{ml})$ and shaked on magnetic stirrer $(150$ cycles $/ \mathrm{min})$ at $37^{\circ} \mathrm{C}$. Withdrawn samples were centrifuged at $12000 \mathrm{rpm}$ and analyzed using UV spectrophotometry at $322 \mathrm{~nm}$.

\section{Ocular Irritancy test}

The prepared nanoparticles belonging to optimized batch were evaluated for in-vivo performance in Albino rabbits. They were manipulated suitably for experimental conditions. Eyes were marked as test and control respectively. The control eyes received no sample while the test eyes received the nanoparticles, and observed for the ocular irritancy. The protocol was approved by Institutional Animal Ethical Committee. ${ }^{17}$

\section{Accelerated (Physical) Stability studies}

$\mathrm{ICH}$ (International Conference of Harmonization) guidelines were followed to carry out the stability study of optimized formulation. The optimized formulation was stored at accelerated conditions $\left(40^{\circ} \pm 2^{\circ} \mathrm{C} / 75 \% \pm 5 \%\right.$ $\mathrm{RH})$ for six months respectively and reckoned, for released characteristics, at predetermined time period. ${ }^{18}$

\section{RESULTS AND DISCUSSION FTIR analysis}

The FTIR spectra of pure drug resulted in characteristic peaks which resembled with those obtained with the combinations. In the spectrum of ketorolac tromethamine (Figure 2A), major peaks (3,625 cm-1; NH stretch); $1,157 \mathrm{~cm}^{-1} ; \mathrm{C}=\mathrm{O}$ stretch (diaryl ketone); $1,625 \mathrm{~cm}^{-1}$; $\mathrm{C}-\mathrm{C}$ stretch (aromatic stretching); and $3,650 \mathrm{~cm}^{-1} ; \mathrm{OH}$ (acid); $2679 \mathrm{~cm}^{-1}$; CH stretching vibration, $1172 \mathrm{~cm}-1$;

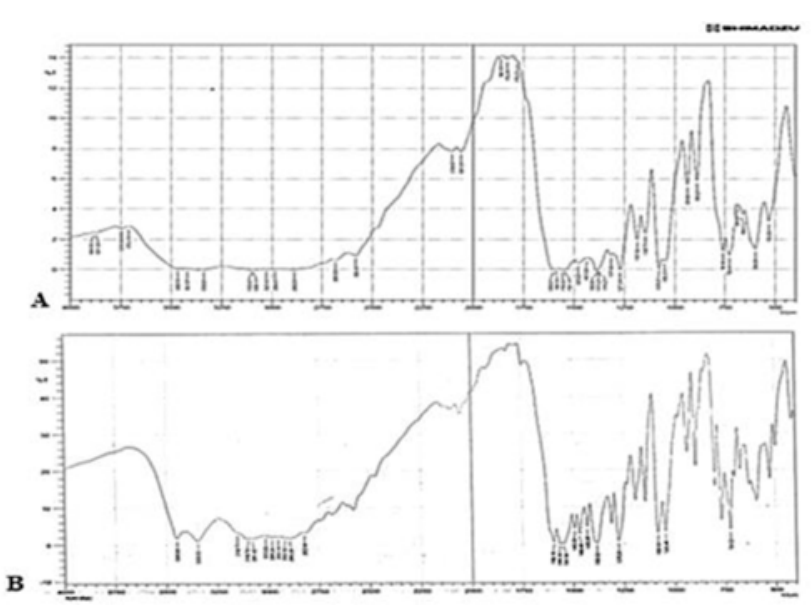

Figure 2: FTIR spectra of (A) Pure drug (Ketorolac tromethamine), (B) Ketorolac tromethamine and chitosan.

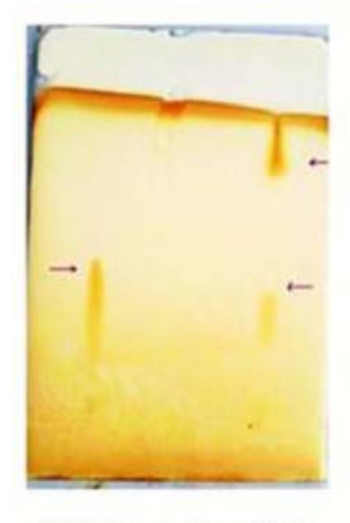

(A) Pure drog (B) Drog * Chitoun

Figure 3: TLC image of ketorolac tromethamine (pure drug) and drug with Chitosan.

$\mathrm{C}-\mathrm{O}-\mathrm{C}$ and $1908 \mathrm{~cm}-1 ; \mathrm{NH}_{2}$, were observed in spectra obtained with chitosan (Figure 2B). Hence, drug polymer compatibility was confirmed by confinement of distinctive peaks of pure drug in its combination with chitosan. ${ }^{19}$

\section{Thin Layer Chromatography (TLC) Method}

Nearly similar $\mathrm{R}_{\mathrm{f}}$ values of the drug alone and its combinations with selected polymer confirmed their compatibility. $\mathrm{R}_{\mathrm{f}}$ value of pure drug i.e. ketorolac 


\begin{tabular}{|c|c|c|c|c|c|c|}
\hline \multicolumn{7}{|c|}{ Table 2: Summary of Regression Analysis Results for Particle size. } \\
\hline Source & $\begin{array}{c}\text { Sum of } \\
\text { Squares }\end{array}$ & df & Mean Square & F-value & p-value & Remark \\
\hline Model & 1915.28 & 5 & 383.06 & 710.34 & $<0.0001$ & significant \\
\hline A-Chitosan & 1683.38 & 1 & 1683.38 & 3121.64 & $<0.0001$ & \\
\hline B-Sodium tri poly phosphate & 212.42 & 1 & 212.42 & 393.90 & 0.0003 & 0.0383 \\
\hline AB & 6.76 & 1 & 6.76 & 12.54 & 0.0168 & \\
\hline A $^{2}$ & 12.67 & 1 & 12.67 & 23.49 & 0.7474 & \\
\hline B $^{2}$ & 0.0672 & 1 & 0.0672 & 0.1247 & & \\
\hline Residual & 1.62 & 3 & 0.5393 & & & \\
\hline
\end{tabular}

\begin{tabular}{|c|c|c|c|c|c|c|}
\hline Source & $\begin{array}{l}\text { Sum of } \\
\text { Squares }\end{array}$ & df & Mean Square & F-value & p-value & Remark \\
\hline Model & 490.48 & 5 & 98.10 & 26807.69 & $<0.0001$ & significant \\
\hline A-Chitosan & 436.74 & 1 & 436.74 & $1.194 \mathrm{E}+05$ & $<0.0001$ & \\
\hline B-Sodium tri poly phosphate & 53.16 & 1 & 53.16 & 14528.42 & $<0.0001$ & \\
\hline$A B$ & 0.0676 & 1 & 0.0676 & 18.47 & 0.0232 & \\
\hline$A^{2}$ & 0.4449 & 1 & 0.4449 & 121.59 & 0.0016 & \\
\hline $\mathrm{B}^{2}$ & 0.0697 & 1 & 0.0697 & 19.04 & 0.0222 & \\
\hline Residual & 0.0110 & 3 & 0.0037 & & & \\
\hline Cor Total & 490.49 & 8 & & & & \\
\hline
\end{tabular}

tromethamine was found to be 0.539 and with chitosan it was 0.538 (Figure 3). Similar results were shown by Dhiraj A. Khairnar et al. (2014). ${ }^{20}$

\section{Formulation, Optimization and Evaluation}

In the present investigation, selected independent variables were amount of chitosan and TPP while the particle size and percentage drug entrapment was selected as dependent variables. The selected independent variables were studied at different levels to observe their individual as well as interactive effects.

Particle size of prepared nanoparticles ranged between 155.5- $200.4 \mathrm{~nm}$ and quadratic model was best suited for the data which was validated by ANOVA. As mentioned in Table 2, the Model F-value is 710.34, which implies that model is significant. Moreover, the factor A had shown more effect on Particle size of nanoparticles with F-value of $3121.64(p<0.0001)$ than factor B with F-value of $393.90(p<0.05)$. The predicted $\mathrm{R}^{2}$ of 0.9898 was significantly correlated with adjusted $\mathrm{R}^{2}$ of 0.9977 ; i.e. the difference is less than 0.2. Signal to noise ratio greater than 4 is desirable, and in the present study, it is 75.719 that indicated an adequate signal.

Polynomial equation thus generated was as shown below (equation 1):
Particle size $(\mathrm{nm})=181.61-16.75 \mathrm{~A}-5.95 \mathrm{~B}-1.30 \mathrm{AB}-2.5 \mathrm{~A}^{2}+1.8 \mathrm{~B}^{2} \quad$ Eq. 1

As shown in Figure 4a, the particle size decreased significantly with increase in concentrations of both factors i.e. chitosan and TPP which was presented in the form of contour and 3D response surface plots. It is already reported that as the concentration of chitosan and TPP increased, particle size decreased accordingly. ${ }^{21-22}$

Second dependent factor was chosen as percent (\%) drug entrapment. Entrapment efficiency of prepared batches (A1-B3) was found between 38.86\%-61.91\%. As shown in Table 3, the Model F-value is 26807.69, which implies that model is significant. Both factors $A$ and $B$ had similar effect on entrapment efficiency of nanoparticles with F-value of $1.194 \mathrm{E}+05$ and 14528.42 respectively at $p<0.0001$. The predicted $\mathrm{R}^{2}$ of 0.9998 was in correlation with adjusted $\mathrm{R}^{2}$ of 0.9999 ; i.e. the difference is less than 0.2. Signal to noise ratio was 466.0; indicated an adequate signal.

Polynomial equation thus generated was as shown below (equation 2):

Entrapment efficiency $(\%)=49.61-8.53 \mathrm{~A}-2.98 \mathrm{~B}-0.13 \mathrm{AB}-0.47 \mathrm{~A}^{2}+0.19 \mathrm{~B}^{2} \quad$ Eq. 2 


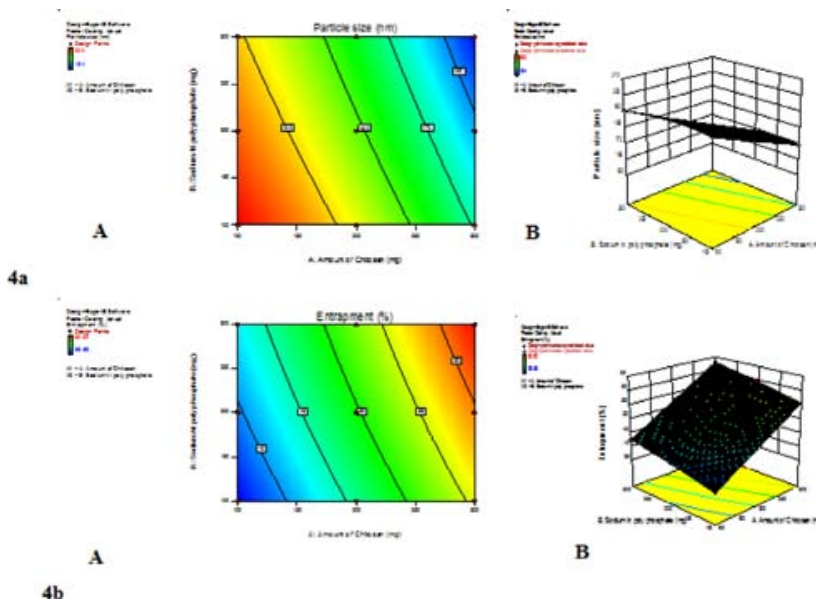

Figure 4: Contour (A) and 3D response surface (B) plots of showing the effect of Chitosan and sodium TPP on Particle size, $4 \mathrm{~b}$. Contour $(A)$ and 3D response surface $(B)$ plots showing the impact of Chitosan and sodium TPP on Entrapment efficiency.
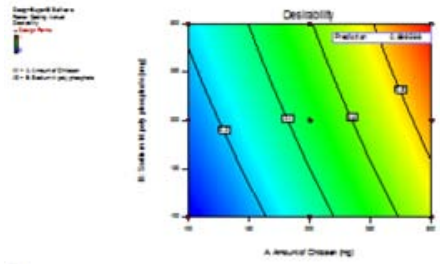

$\mathbf{A}$

Figure 5: Desirability Contour and 3D graph of KT nanoparticulate batch (OKT).

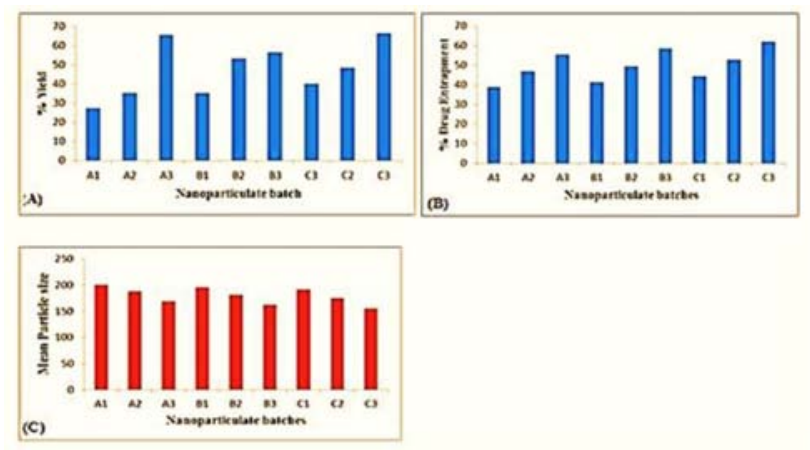

Figure 6: Evaluation Parameters for Ketorolac tromethamine nanoparticles (batches A1-C3), (A) Percentage (\%) yield, (B) Percentage drug entrapment, (C) Mean Particle size.

From the polynomial equation, it was shown that when factors i.e. $\mathrm{A}$ and $\mathrm{B}$ increased, the drug entrapment into polymer was also increased. It is reported that a decrease in weight ratio of CS/TPP, decreases the encapsulation efficiency of nanoparticles pertaining to more compact solid-matrix structure that had led to the increasing amount of nanoparticles formation, resulting in the increased nanoencapsulation. ${ }^{22}$ Moreover, the maximum polymer and surfactant (TPP) concentration give more encapsulation efficiency and vice-versa (Figure 4b). It may be due to fact that increased size of polymer can encapsulate more drug, but more surfactant also accelerate the encapsulation by increasing the binding contact between drug and polymer in emulsion stage. ${ }^{23}$ Desirability function was used for optimization to obtain the levels of process parameters in which particle size was kept at minimum and entrapment efficiency at maximum. Based on the results obtained from predicted solution (Figure 5) given by optimization study, a checkpoint batch (OKT) was prepared and considered as optimized batch for further studies.

\section{Physicochemical evaluation of KT nanoparticles Percentage yield and Drug entrapment efficiency}

Percentage yield of prepared nanoparticles (batches yield $(58.9 \%)$ was obtained with batch C. Nanoencapsulation of therapeutic agents increases their targeting ability, specificity and efficacy. Moreover, they protect the drug from earlier degradation; improve bioavailability and cellular uptake and controlled drug release..$^{24-25}$ Percent (\%) drug entrapment was found between 38.86\%-61.91\% with batches A1-C3.

\section{Particle size analysis and Zeta potential}

It is reported that particle size has profound effect on drug release. Smaller the nanoparticle size resulted in greater surface area which leads to quick drug delivery. ${ }^{26}$ Mean particle size consisting of all batches were found in the range of 155.5- $200.4 \mathrm{~nm}$. Nanoparticles comprised of batch C3 had smallest (155.5 nm) particle size. Nanoparticles with zeta potentials of less than $-30 \mathrm{mV}$ or greater than $+30 \mathrm{mV}$ are considered strongly anionic and strongly cationic, respectively and they show greater colloidal stability. Since most biological cells have negative zeta potential; thus zeta potential of nanoparticulate systems must be slightly negative so that they do not stick non-specifically to cells but interact through a receptor mediated interaction. ${ }^{27}$ The zeta potential of prepared nanoparticles (batch A1-C3) ranged between $(-9.58)$ to $(-18.5) \mathrm{mV}$.

Percentage yield, entrapment efficiency and mean particle size data of prepared batches (A1-C3) has shown in Figure 6.

\section{Surface Morphology}

The Scanning Electron Microscope (SEM) is most versatile instrument available for examination and analysis of morphology and chemical characterization of nanomaterials. It is an important tool for characterization of particle morphology and its distribution. Ketorolac 

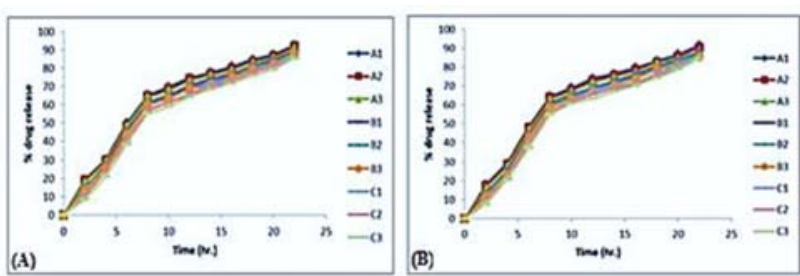

Figure 7: In-vitro drug release data of KT nanoparticles (batches A1- C3) in (A) pH 7.4 PBS, (B) Simulated Tear Fluid.
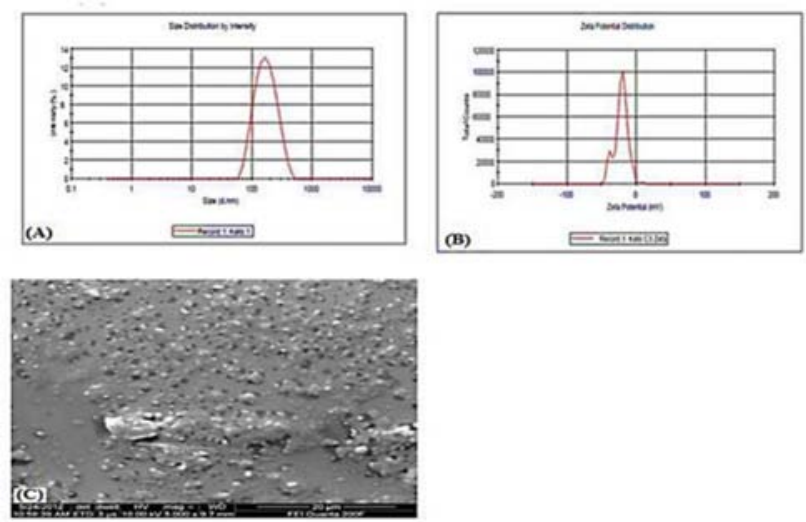

Figure 8: Evaluation Parameters for Optimized batch (OKT) of Ketorolac tromethamine (A) Particle size, (B) Zeta Potential, (C) Scanning Electron Microscopic image.

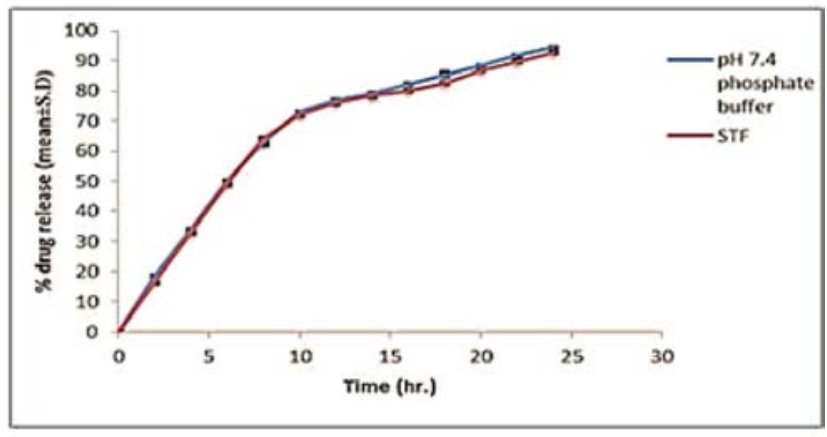

Figure 9: In-vitro release data of OKT in pH 7.4 PBS and STF (mean \pm Standard deviation).

tromethamine nanoparticles (batches A1-C3) were having rough surfaces with spherical in shape. ${ }^{28}$

\section{In-vitro release study}

The release rate decreased with increase in cross-linking density. A dense matrix of the nanoparticles might exhibit slower release rate of the drug. ${ }^{29}$ Percentage drug release from Ketorolac tromethamine nanoparticles was
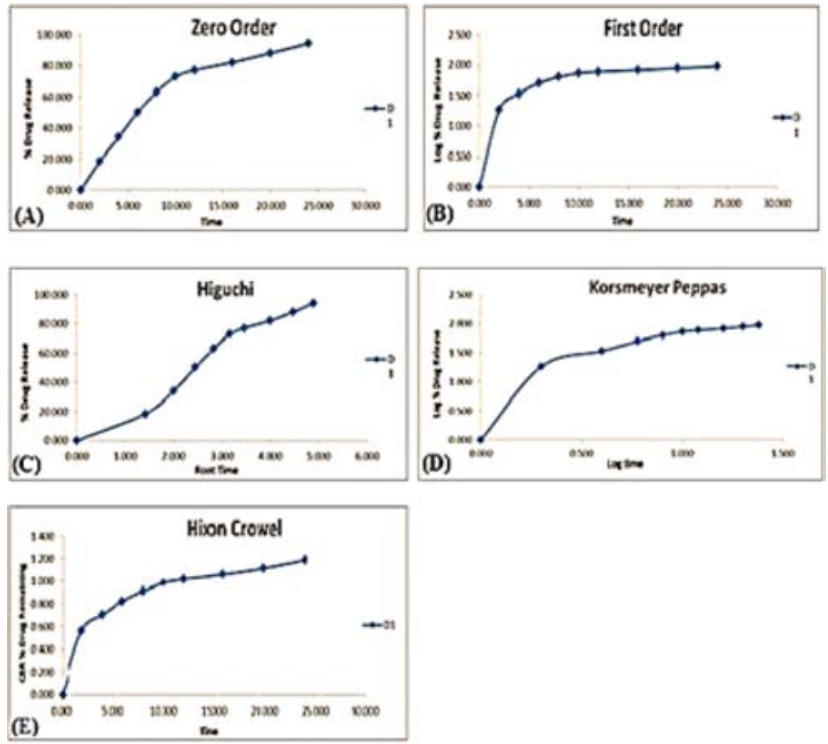

Figure 10: Release Kinetic graphs of OKT (A) Zero order graph, (B) First order graph, (C) Higuchi graph, (D) Korsmeyer peppas graph, (E) Hixon Crowel graph in STF.

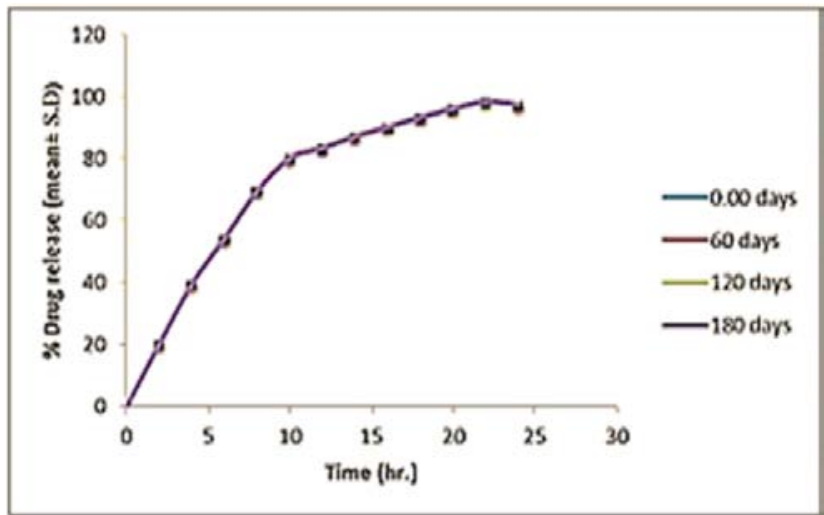

Figure 11: Drug release data of optimized batch (OKT) of Ketorolac tromethamine nanoparticles obtained during stability study (mean \pm S.D).

found to be in $90.23-96.87 \%$ and $89.22-95.65 \%$ in $\mathrm{pH}$ 7.4 PBS and STF respectively (Figure 7).

\section{Evaluation Parameters for Optimized batch (OKT)}

The optimized batch thus prepared was having Percentage yield (66.4\%), \% Entrapment Efficiency (61.65\%), Particle size (153.9 nm), Zeta Potential (-21.8) and percentage drug release $(94.368 \pm 0.181$ and $92.797 \pm 0.150 \%$ in PBS and STF ( $\mathrm{pH}$ 7.4) respectively) (Figure 8, 9). Results of release kinetic study revealed that drug dissolution followed Zero order release kinetics model (Figure 10).

\section{Ocular Irritancy test}

No irritation was observed. 


\section{Accelerated Stability studies}

Nanoparticulate optimized batch was found to be almost absolutely stable at storage conditions. The percentage drug release from prepared optimized batch of ketorolac tromethamine was found to be $98.086 \pm 0.204 \%$ at 180 days (Figure 11).

\section{CONCLUSION}

It was concluded that the novel formulations being reported by the present worker possessed in-built advantage in having longer ocular residence time and thus enhancing the patient compliance besides significant ocular availability.

\section{ACKNOWLEDGEMENT}

The corresponding author acknowledges the Department of Pharmacy, Teerthanker Mahaveer University for conducting the research work.

\section{CONFLICT OF INTEREST}

The authors report no conflicts of interest.

\section{ABBREVIATIONS}

KT: Ketorolac tromethamine; STF: Simulated Tear Fluid; TLC: Thin Layer Chromatography; FTIR: Fourier Transmission Infra-Red; CS: Chitosan; Na-TPP: sodium tri-polyphosphate; ICH: International Conference of Harmonization; OKT: Optimized batch of Ketorolac tromethamine; PBS: Phosphate buffer Saline; STF: Simulated Tear Fluid; RH: Relative humidity, Rf: Retention factor.

\section{REFERENCES}

1. Ahuja M, Dhake AS, Sharma SK, Majumdar DK. Topical Ocular Delivery of NSAIDs. AAPS J. 2008;10(2):229-41.

2. www.iitbhu.ac.in/Rao_et_al.pdf, date of access 2017.4 .12

3. www.promedgroup.com/eye-inflammation.html. date of access 2015.20.8

4. Schoenberger SD, Kim SJ. Non-Steroidal anti-inflammatory drugs for retinal diseases. Int J Inflamm. 2013:1-8.

5. Bourlais CL, Acar L, Zia H, Sado PA, Needham T, Leverge R. Ophthalmic drug delivery systems--recent advances. Prog Retin Eye Res. 1998;17(1):33-58.

6. Janagam DR, Wu L, Lowe TL. Nanoparticles for drug delivery to the anterior segment of the eye. Adv Drug Deliv Rev. 2017;122:31-64.

7. Nagarwal RC, Kant S, Singh PN, Maiti P, Pandit JK. Polymeric nanoparticulate system: a potential approach for ocular drug delivery. J Control Release. 2009;136(1):2-13.
8. Battaglia L, Serpe L, Foglietta F, Muntoni E, Gallarate M, Rodriguez ADP, et al. Application of lipid nanoparticles to ocular drug delivery. Expert Opin Drug Deliv. 2016; 13(12):1743-57.

9. Patel A, Patel M, Yang X, Mitra AK. Recent advances in protein and Peptide drug delivery: a special emphasis on polymeric nanoparticles. Protein Pept Lett. 2014;21(11):1102-20.

10. Wang JJ, Zeng ZW, Xiao RZ, Xie T, Zhou GL, Zhan XR, et al. Recent advances of chitosan nanoparticles as drug carriers. Int $\mathrm{J}$ Nanomedicine. 2011;6:765-74.

11. Krishna SA, Amareshwar P, Chakravarty P. Chitosan nanoparticles as a drug delivery system. Res J Pharma Bio and Chem Sci. 2011;1(3):474-84.

12. Sandoval HP, Castro LEFD, Vroman DT, Solomon KD. A review of the use of ketorolac tromethamine $0.4 \%$ in the treatment of post-surgical inflammation following cataract and refractive surgery. Clin Ophthalmol. 2007;1(4):367-71.

13. Yilmaz T, Cordero-Coma M, Gallagher MJ. Ketorolac therapy for the prevention of acute pseudophakic cystoid macular edema: a systematic review. Eye. 2012;26(2):252-8.

14. Kumar BS, Kunchu K, Mani RK. Evaluation of Ketorolac tromethamine Microspheres by Chitosan/Gelatin B Complex Coacervation. Sci Pharm. 2010;78(1):79-92.

15. Fathalla ZMA, Khaled KA, Hussein AK, Alany RG, Vangala A. Formulation and corneal permeation of ketorolac tromethamine-loaded chitosan nanoparticles. Drug Dev Ind Pharm. 2016;42(4):514-24.

16. Bhatia M, Gupta S. Formulation, Characterization and in vitro-in vivo evaluation of Ketorolac loaded Solid lipid nanoparticles for transdermal delivery. Der Pharmacia Lettre. 2016;8(10):213-21.

17. Sirish V, Sadhna K, Nalini S, Sadanandam M. Formulation and Evaluation of ion activated ocular gels of ketorolac tromethamine. International Journal of Current Pharmaceutical Research. 2010;2(3):33-8.

18. ICH Q1A (R) guidelines: Stability testing of New Drug Substance and Product. 2003;1-18.

19. Dea PK, Mallickb S, Mukherjeec B, Senguptaa S, Pattnaik DS, Chakrabortya S. Optimization of In-vitro Permeation Pattern of Ketorolac Tromethamine Transdermal Patches. Iranian J of Pharm. Res. 2011;10(2):193-201.

20. Rathapon A, Chayanid S, Nardauma T, Sirijit P. Effect of Formulation Compositions on Particle Size and Zeta Potential of Diclofenac SodiumLoaded Chitosan Nanoparticles. Int J Pharmacol and Pharmaceutical Sciences. 2013;7(9):568-70.

21. Dhiraj AK, Sanjay PA, Swapnil SG, Rohini HK, Vrushali GK. Development of Thin Layer Chromatographic (TLC) Method for Identification of Ketorolac Tromethamine Salt. IJPCS. 2014:3(2):335-40.

22. Hou D, Gui R, Hu S, Huang Y, Feng Z, Ping Q. Preparation and Characterization of Novel Drug-Inserted-Montmorillonite Chitosan Carriers for Ocular Drug Delivery. Adv in Nanoparticles. 2015;4(3):70-84.

23. Naik J, Lokhande AK, Mishra S, Kulkarni R. Formulation and evaluation of glipizide loaded nanoparticles. Int J of Pharm and Pharm Sci. 2013;5(4):147-51.

24. Kumari A, Singla R, Guliani A, Yadav SK. Nano encapsulation for Drug Delivery. EXCLI Journal. 2014;13:265-86.

25. Greque DMM, Greque DME, Vaz BS, Gonçalves CF, Lisboa C, Costa JA. Nanoencapsulation of the Bioactive Compounds of Spirulina with a Microalgal Biopolymer Coating. J Nanosci Nanotechnol. 2016;16(1):81-91.

26. Hafeez A, Kazmi I. Dacarbazine nanoparticle topical delivery system for the treatment of melanoma. Scientific Reports. 2017;7(1):1-10.

27. Clogston JD, Patri AK. Zeta Potential Measurement. Methods Mol Biol. 2011;697:63-70.

28. Zhou W, Wang ZL. Scanning Microscopy for Nanotechnology: Techniques and Applications. Chapter 1-Fundamentals of SEM. Spinger. 2007:1-40.

29. 29. Kumar SS, Sahaa AK, Kavithab K, Basua SK. Evaluation of clobazam loaded ionically cross-linked microspheres using chitosan. Der Pharmacia Sinica. 2012;3(6):616-23. 


\section{PICTORIAL ABSTRACT}

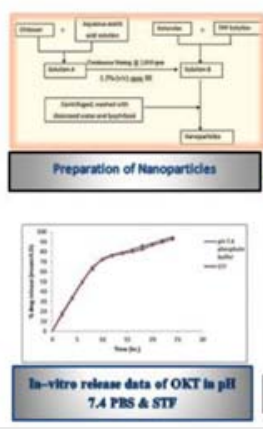

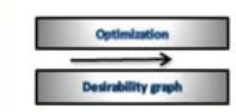

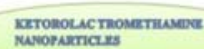

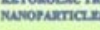

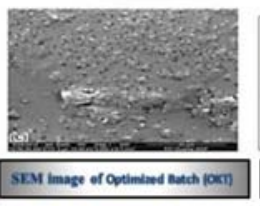

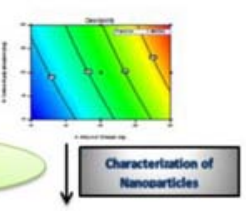

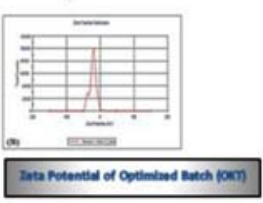

\section{About Authors}

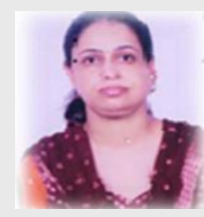

Dr. Shaweta Sharma, M. Pharm., Ph.D., is currently employed as Professor of Pharmaceutics at IIMT College of Pharmacy, Greater Noida. The college is affiliated to AKTU and AICTE. She has completed Ph.D. in 2017 from Teerthanker Mahaveer University, Moradabad, U.P., India. She has been contributing to academics from more than 10 years. She has published articles in many peer reviewed national journals.

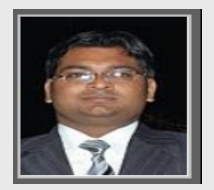

Dr. Akhil Sharma, M. Pharm., Ph.D., is presently working as Professor and Principal at R.J College of Pharmacy, Raipur, Aligarh, U.P., India. He has completed his Ph.D. in 2016 from Teerthanker Mahaveer University, Moradabad, U.P., India. He has been serving the profession of Pharmacy from more than 10 years. He has published articles in many peer reviewed national journals.

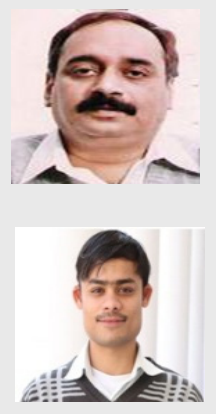

Dr. U.V.S Sara, M.Pharm., Ph.D., is currently working as Professor and Director at Dr. M.C. Saxena Group of institutions, Lucknow, U.P., India. He has completed his B.Pharmacy, M.Pharmacy and Ph.D. from Mangalore University, Mangalore. He has guided 8 Ph.D. candidates (5 Awarded; 1 submitted; 2 Under progress). He has published many articles in several peer reviewed journals of National \& International repute. He is having total Professional experience of more than $22 \mathrm{yrs}$.

Mr. Shekhar singh, M.Pharm., pursuing Ph.D., working as an Assistant Professor at Teerthanker Mahaveer University, Moradabad, U.P., India. He completed his B. Pharmacy from Shivalik College of Pharmacy, Naya Nangal, Punjab and M.Pharm from Teerthanker Mahaveer College of Pharmacy, TMU, Moradabad, U.P., India.

Cite this article: Sharma S, Sharma A, Sara UVS, Singh S. Chitosan Loaded Ketorolac Tromethamine Nanoparticles for Improved Ocular Delivery in Eye Inflammation. Indian J of Pharmaceutical Education and Research. 2018;52(4 Suppl 2):s202-s209. 